\title{
Analisis Insiden Keselamatan Pasien di Rumah Sakit Berdasarkan Pendekatan Beban Kerja dan Komunikasi
}

\author{
Agus Aan Adriansyah", Budhi Setianto ", Nikmatus Sa'adah ${ }^{* *}$, Pinky Ayu Marsela Arindis ${ }^{*}$, Wahyu Eka \\ Kurniawan", Indah Lestari* \\ *Program Studi S1 Kesehatan Masyarakat, Fakultas Kesehatan, Universitas Nahdlatul Ulama Surabaya \\ ***Program Studi S1 Pendidikan Dokter Gigi, Fakultas Kedokteran Gigi, Institut Ilmu Kesehatan Bhakti \\ Wiyata \\ *Email: aan.naufal87@unusa.ac.id
}

\section{ABSTRACT}

Patient safety incidents at Ahmad Yani Islamic Hospital Surabaya increased by $0.3 \%$ in 2019. If it not addressed immediately, these problems can give a negative image to hospitals and patients. An error that appears and has an impact on increasing patient safety incidents, stems from a high workload and poor communication. The purpose of this study was to analyze the role of workload and communication on the occurrence of patient safety incidents in hospitals. This study uses 18 work units as unit analysis that directly provide services to patients. The participants were included the head of work units, the person in charge of the work units and the person in charge of the quality of the work units with a total of 90 people. The primary data were collected using questionnaire instruments in google form. The communication measurement tool uses the Communication Openness Measurement (COM) and the workload uses the Workload Indicator of Staffing Needed (WISN) calculation. Patient safety incident data were collected from the patient safety committee . The analysis was carried out by cross tabulation with interpretation using the Pareto concept. The results showed that most work units (83.3\%) had the low workload, most of work units' communication (61.1\%) were not good and $33.3 \%$ of work units had high patient safety incident rate. In the Pareto concept, the results showed that workload had no effect on patient safety incidents, while communication influenced the number of patient safety incidents. Therefore, hospitals need to fix the pattern and flow of communication as well as the need for information disclosure so that the flow of information becomes more adequate, transfer of knowledge becomes better and employee's understanding of the importance of patient safety in hospitals becomes better.

Keywords : Communication, Hospital, Patient Safety Incident, Workload.

\section{PENDAHULUAN}

Keselamatan pasien merupakan suatu sistem yang membuat pasien lebih aman. Sistem ini meliputi penilaian risiko, identifikasi, pengelolaan risiko pasien, pelaporan dan analisis insiden, kemampuan belajar dari insiden dan tindak lanjutnya, serta implementasi solusi untuk meminimalkan timbulnya risiko dan mencegah terjadinya cedera yang disebabkan oleh kesalahan akibat melaksanakan suatu tindakan atau mengambil tindakan yang seharusnya diambil ${ }^{1}$. Insiden keselamatan pasien adalah setiap kejadian yang tidak disengaja dan kondisi yang mengakibatkan atau berpotensi menimbulkan cedera yang dapat dicegah pada pasien. Berdasarkan data dari Direktorat Jendral Pelayanan Kesehatan, angka kejadian insiden 
keselamatan pasien yang terlaporkan di Indonesia sampai Tahun 2019 sudah mencapai 10.570 kasus. Di samping itu, menurut data dari $\mathrm{WHO}$, terdapat 134 juta kejadian buruk setiap tahun di rumah sakit LMICs, yang berkontribusi pada 2.6 juta kematian akibat perawatan yang tidak aman ${ }^{2}$.

Berdasarkan data yang dihimpun, terdapat peningkatan kejadian insiden keselamatan di RS Islam Surabaya sebesar 0,3\% di tahun 2019 dibandingkan tahun-tahun sebelumnya. Jumlah insiden yang terjadi didominasi oleh kejadian nyaris cedera dengan grading hijau. Di samping itu, budaya keselamatan pasien di RS Islam Surabaya juga masih lemah di beberapa kategori, diantaranya terdapat penilaian negatif pada kerja tim antar unit $(27,7 \%)$, kerja tim antar unit $(42,1 \%)$, pelaporan insiden $(20,0 \%)$, dukungan manajemen $(11,6 \%)$ dan persepsi terhadap keselamatan pasien $(17,1 \%)$.

Penelitian ini dibatasi pada faktor organisasi karena organisasi merupakan salah satu faktor penting dalam mewujudkan mutu dan keselamatan pasien di rumah sakit. Faktor organisasi yang diteliti dari penelitian ini adalah beban kerja dan komunikasi. Penting untuk menjadi sebuah perhatian bahwa sebuah

kesalahan yang muncul dan berdampak pada meningkatnya insiden keselamatan pasien, bermula dari beban kerja yang terlalu tinggi dan berlanjut pada komunikasi yang tidak berjalan dengan baik serta tidak adanya keterbukaan komunikasi, baik antar staf, staf dengan atasan, maupun staf dengan pasien ${ }^{3,4,5}$. Beban kerja yang berlebihan akan menimbulkan berbagai efek yaitu kelelahan fisik-mental dan reaksi-reaksi emosional seperti sakit kepala, kelalaian, lupa dan mudah marah sehingga berpotensi membahayakan petugas serta menimbulkan insiden ${ }^{3}$. Sementara itu, keselamatan pasien juga perlu ditunjang dengan alur informasi yang baik dan proses komunikasi bagi setiap pihak yang bertanggung jawab dalam budaya keselamatan pasien ${ }^{4}$. Oleh sebab itu, tujuan penelitian ini adalah untuk menganalisis bagaimana peran sebuah beban kerja dan komunikasi terhadap terjadinya insiden keselamatan pasien di Rumah Sakit Islam Surabaya Ahmad Yani.

\section{METODE PENELITIAN}

Metode yang digunakan dalam penelitian ini adalah deskriptif analitik dengan rancang bangun cross sectional. Unit analisis penelitian ini merupakan seluruh unit kerja pelayanan yang memberikan layanan langsung kepada pasien, yang berjumlah 18 unit kerja. Partisipan meliputi 21 kepala unit kerja, 51 penanggung jawab unit kerja dan 18 penanggung jawab mutu unit kerja.

Variabel yang diteliti meliputi beban kerja, komunikasi dan insiden keselamatan pasien. Data primer dikumpulkan dengan kuesioner yang dibuat dalam google form. Data untuk variabel komunikasi dikumpulkan dengan menggunakan kuesioner Communication Openness Measurement (COM) dengan 19 pernyataan. Data yang terkumpul, kemudian dikategorikan menjadi dua yaitu kategori kurang $(\leq 3,2)$ dan kategori baik $(>3,2)$. Kemudian, data variabel beban kerja dikumpulkan menggunakan perhitungan yang sudah ditentukan berdasarkan rumus WISN. Data yang terkumpul, kemudian dikategorikan menjadi dua yaitu kategori beban kerja tinggi (Ratio <1) dan kategori beban kerja rendah (Ratio $>1$ ).

Beban kerja pada setiap unit kerja yang memberikan pelayanan, dapat dihitung menggunakan tahapan sebagai berikut:

1. Menetapkan Waktu Kerja Tersedia (WKT)

WKT $=[\mathrm{A}-(\mathrm{B}+\mathrm{C}+\mathrm{D}+\mathrm{E})] \times \mathrm{F}$
Keterangan:
$\mathrm{A}=$ Hari kerja,
$\mathrm{B}=$ Cuti tahunan,
$\mathrm{C}=$ Pendidikan dan Pelatihan,
$\mathrm{D}=$ Hari libur nasional,
$\mathrm{E}=$ Ketidakhadiran kerja,
$\mathrm{F}=$ Waktu kerja.
Menghitung Standar Beban Kerja (SBK)
SBK = Waktu kerja tersedia
Mean waktu produksi 1 kegiatan
pokok

3. Menghitung Standar Kelonggaran (SK)

SK $=\quad$ Rata-rata waktu kelonggaran Waktu kerja tersedia

4. Menghitung Kebutuhan Tenaga (KT)

$$
\mathrm{KT}=\frac{\text { Kuantitas kegiatan pokok }+\mathrm{SK}}{\text { Standar beban kerja }}
$$


Tahapan terakhir adalah melakukan perhitungan Ratio WISN, yaitu:

$\mathrm{WISN}=\mathrm{A} \times \mathrm{B}+\mathrm{C}$

Difference $=\mathrm{a}-\mathrm{b}$

Ratio $=\mathrm{a} / \mathrm{b}$

Keterangan:

A = Aktivitas utama layanan kesehatan,

$\mathrm{B}=$ Aktivitas penunjang,

$\mathrm{C}=$ Aktivitas tambahan,

$\mathrm{a}=$ Jumlah SDM yang ada,

$\mathrm{b}=$ Jumlah SDM menurut perhitungan WISN

Data variabel insiden keselamatan pasien diperoleh dari PMKP RS Islam Surabaya, yang kemudian dikelompokkan berdasarkan unit kerja, dihitung dampak serta probabilitas kejadian insiden, kemudian dimasukkan dalam tabel matriks risiko yang dengan pemberian bobot penilaian oleh peneliti. Penentuan tinggi rendahnya angka insiden di setiap unit kerja didapatkan dari rata-rata jumlah insiden semua unit kerja. Data yang telah diperoleh, kemudian dikategorikan menjadi dua yaitu insiden kategori rendah (angka insiden <11,8) dan insiden kategori tinggi $(\geq 11,8)$.

Analisis pengaruh antara beban kerja dan komunikasi terhadap insiden keselamatan pasien menggunakan tabulasi silang. Hasil tabulasi silang selanjutnya diinterpretasikan dengan menggunakan konsep pareto, yaitu berpengaruh jika selisih dari perhitungannya sebesar $>20 \%$.

\section{HASIL DAN PEMBAHASAN}

Analisis beban kerja dan komunikasi terhadap insiden keselamatan pasien dilakukan pada seluruh unit kinerja yang berhubungan dengan pelayanan yang terdiri dari 18 unit kerja RS Islam Surabaya Ahmad Yani. Berikut penyajian hasil selengkapnya.

\section{Insiden Keselamatan Pasien}

Insiden keselamatan pasien (IKP) yang muncul dapat memberi dampak negatif bagi rumah sakit dan pasien sebagai penerima layanan kesehatan. Pelaporan adalah salah satu unsur penting dalam keselamatan pasien. Informasi yang valid pada pelaporan yang dibuat, dapat menjadi bahan yang baik oleh organisasi untuk proses pembelajaran. Organisasi dapat belajar dari pengalaman sebelumnya dan akan mengasah kemampuan organisasi dalam mengidentifikasi faktor risiko lebih dini sehingga dapat mencegah maupun mengurangi terjadinya insiden. Beberapa hal yang harus diperhatikan dari pelaporan insiden keselamatan pasien, yaitu jenis insiden dan grading insiden dan ketepatan pelaporan insiden. Gambaran insiden keselamatan pasien dapat dilihat pada Tabel 1 dan Tabel 2.

Tabel 1. Gambaran Angka Insiden Keselamatan Pasien, Beban Kerja dan Komunikasi Unit Kerja Periode Semester 2 Tahun 2019

\begin{tabular}{llcccccc}
\hline \multirow{2}{*}{ No. Unit Kerja } & Keselamatan Pasien & \multicolumn{2}{c}{ Beban Kerja } & \multicolumn{2}{c}{ Komunikasi } \\
\cline { 3 - 7 } & & IKP & Kategori & Skor & Kategori & Skor & Kategori \\
\hline 1 & Rawat Jalan & 57,2 & Tinggi & 0,9 & Tinggi & 3,1 & Kurang \\
\hline 2 & IGD & 16,9 & Tinggi & 1,2 & Rendah & 3,1 & Kurang \\
\hline 3 & R. Tan im, Muzdalifah \& Jeddah & 13,3 & Tinggi & 1,4 & Rendah & 3,4 & Baik \\
\hline 4 & R. Shofa & 13,0 & Tinggi & 1,1 & Rendah & 3,2 & Kurang \\
\hline 5 & Farmasi & 12,3 & Tinggi & 1,4 & Rendah & 3,1 & Kurang \\
\hline 6 & R. Hijir Ismail & 12,0 & Tinggi & 1,1 & Rendah & 3,1 & Kurang \\
\hline 7 & Hemodialisis & 10,0 & Rendah & 0,8 & Tinggi & 3,0 & Kurang \\
\hline 8 & Kamar Operasi & 9,5 & Rendah & 1,1 & Rendah & 3,1 & Kurang \\
\hline 9 & R. Makkah & 9,0 & Rendah & 1,1 & Rendah & 3,1 & Kurang \\
\hline 10 & Laboratorium & 9,0 & Rendah & 1,0 & Rendah & 3,1 & Kurang \\
\hline 11 & R. Mina & 8,5 & Rendah & 1,1 & Rendah & 3,4 & Baik \\
\hline 12 & R. Thoif \& Bersalin & 7,5 & Rendah & 1,0 & Rendah & 3,5 & Baik \\
\hline 13 & Radiologi & 7,5 & Rendah & 1,0 & Rendah & 3,4 & Baik \\
\hline 14 & R. Madinah & 7,3 & Rendah & 1,2 & Rendah & 3,2 & Kurang \\
\hline 15 & R. Arofah & 5,7 & Rendah & 1,3 & Rendah & 3,3 & Baik \\
\hline
\end{tabular}




\begin{tabular}{llcccccc}
\hline \multirow{2}{*}{ No. } & Unit Kerja & \multicolumn{2}{c}{ Keselamatan Pasien } & \multicolumn{2}{c}{ Beban Kerja } & \multicolumn{2}{c}{ Komunikasi } \\
\cline { 3 - 7 } & & IKP & Kategori & Skor & Kategori & Skor & Kategori \\
\hline 16 & R. Multazam & 5,5 & Rendah & 0,7 & Tinggi & 3,2 & Kurang \\
\hline 17 & ICU & 4,3 & Rendah & 1,9 & Rendah & 3,7 & Baik \\
\hline 18 & R. Zam-zam & 4,0 & Rendah & 1,7 & Rendah & 3,7 & Baik \\
\hline
\end{tabular}

Tabel 2. Rekapitulasi Kategori, Jenis dan Grading Insiden Keselamatan Pasien

\begin{tabular}{lrrr}
\hline No. & Distribusi IKP & n & \multicolumn{1}{c}{$\%$} \\
\hline \multicolumn{1}{l}{ Kategori IKP pada Unit Kerja } \\
\hline $1 \quad$ Tinggi & 6 & 33,3 \\
\hline $2 \quad$ Rendah & 12 & 66,7 \\
\hline \multicolumn{2}{l}{ Total } & 18 & 100,0 \\
\hline Jenis IKP & 269 & 83,8 \\
\hline $1 \quad \begin{array}{l}\text { Kejadian Nyaris Cidera } \\
\text { (KNC) }\end{array}$ & 24 \\
\hline 2 & $\begin{array}{l}\text { Kejadian Tanpa Cidera } \\
\text { (KTC) }\end{array}$ & 7,5 \\
\hline 3 & $\begin{array}{l}\text { Kejadian Tidak Diharapkan } \\
\text { (KTD) }\end{array}$ & 28 & 8,7 \\
\hline 4 & Sentinel & 0 & 0,0 \\
\hline Total & 321 & 100,0 \\
\hline Grading IKP & 22 & 6,9 \\
\hline 1 & Biru & 294 & 91,6 \\
\hline 2 & Hijau & 5 & 1,6 \\
\hline 3 & Kuning & 0 & 0,0 \\
\hline 4 & Merah & 321 & 100,0 \\
\hline Total & & \\
\hline
\end{tabular}

Tabel 1 dan Tabel 2 menunjukkan bahwa dari 18 unit kerja layanan di RSI Ahmad Yani, terdapat 6 unit kerja $(33,3 \%)$ yang memiliki angka IKP tinggi, yaitu Farmasi, Ruang Hijr Ismail, Ruang Shofa Marwah, Ruang Tan'im Muzdhalifah Jeddah, Rawat Jalan, IGD. Unit kerja yang paling tinggi IKP nya adalah unit Rawat Jalan.. Sementara itu, selama periode semester 2 tahun 2019, jenis insiden keselamatan pasien terbanyak yang dilaporkan adalah KNC $(83,8 \%)$ dan grading insiden keselamatan pasien terbanyak yang dilaporkan adalah Hijau $(83,8 \%)$.

\section{Beban kerja}

Beban kerja adalah kondisi uraian tugas dari sebuah pekerjaan yang harus diselesaikan pada batas waktu tertentu ${ }^{1}$. Beban kerja termasuk salah satu aspek yang harus diperhatikan oleh setiap organisasi, karena merupakan salah satu faktor yang memengaruhi kinerja karyawan. Pemberian beban kerja kepada pegawai harus diikuti oleh bagaimana kemampuan seorang pimpinan dalam mengidentifikasi kemampuan dan keterampilan pegawainya. Hal tersebut bertujuan agar beban kerja yang diberikan kepada pegawai dapat dilaksanakan secara efektif ${ }^{3,4}$. Gambaran beban kerja pegawai dapat dilihat pada Tabel 1.Metode perhitungan yang digunakan untuk mengukur beban kerja dalam penelitian ini adalah dengan WISN. Menurut Munandar (2001) beban kerja adalah suatu kondisi dari pekerjaan dengan uraian tugasnya yang harus diselesaikan pada batas waktu tertentu ${ }^{1}$. Tabel 1 menunjukkan bahwa dari 18 unit kerja layanan di RSI Ahmad Yani, terdapat 3 unit kerja $(16,7 \%)$ yang memiliki tingkat beban kerja tinggi, yaitu unit Rawat Jalan, Hemodialisis dan Ruang Multazam. Tiga unit kerja tersebut memang memiliki beban kerja tinggi mengingat banyak jumlah pasien yang perlu ditangani.

Sementara itu, efek beban kerja terhadap insiden keselamatan pasien disusun dalam tabulasi silang dengan analisis menggunakan pendekatan konsep pareto 20:80. Artinya, $80 \%$ kejadian diakibatkan oleh $20 \%$ penyebabnya ${ }^{8}$ Apabila penyebabnya $>20 \%$, maka terdapat pengaruh beban kerja terhadap insiden keselamatan pasien. Hasil selengkapnya tersaji pada Tabel 3 berikut ini.

Tabel 3. Analisis Beban Kerja Terhadap Insiden Keselamatan Pasien

\begin{tabular}{lccc}
\hline \multirow{2}{*}{$\begin{array}{l}\text { Beban } \\
\text { kerja }\end{array}$} & \multicolumn{2}{c}{ Insiden Keselamatan Pasien } & \multirow{2}{*}{ Total } \\
\cline { 2 - 4 } & Rendah & Tinggi & \\
\cline { 2 - 4 } Rendah & $\mathbf{n}(\boldsymbol{\%})$ & $\mathbf{n}(\boldsymbol{\%})$ & $\mathbf{n}(\boldsymbol{\%})$ \\
\hline Tinggi & 10 & 5 & 15 \\
& $(66,7)$ & $(33,3)$ & $(100,0)$ \\
\hline Total & 2 & 1 & 3 \\
& $(66,7)$ & $(33,3)$ & $(100,0)$ \\
\hline
\end{tabular}


Tabel 3 menjelaskan bahwa mayoritas insiden keselamatan pasien yang terjadi masuk dalam kategori rendah, meskipun distribusi beban kerjanya rendah maupun tinggi. Selisih persentase antara kategori pada beban kerja rendah maupun tinggi adalah sebesar $0 \%(<20 \%)$ yang dapat disimpulkan bahwa beban kerja unit tidak memengaruhi terjadinya insiden keselamatan pasien di RS Islam Ahmad Yani Surabaya ${ }^{5}$. Beban kerja yang rendah dari hasil penelitian ini dapat disebabkan karena pengukuran beban kerja dilaksanakan saat masa pandemi, sehingga jumlah pasien saat itu tergolong lebih sedikit dari masa sebelum pandemi ${ }^{6,7}$.

Hasil penelitian ini juga menunjukkan ada satu unit kerja dengan beban kerja tinggi diikuti dengan insiden keselamatan pasien yang tinggi di unit kerja tersebut, yaitu unit rawat jalan ${ }^{8,9}$. Hal ini bisa disebabkan karena jumlah kunjungan yang tinggi berbanding terbalik dengan jumlah perawat yang ada di rawat jalan ${ }^{10}$. Perawat di unit rawat jalan dalam melaksanakan tugasnya terbagi menjadi dua shift kerja, satu perawat dapat melayani pasien di dua poli yang berbeda dengan jadwal dokter yang bersamaan sehingga dapat menyebabkan konsentrasi perawat juga terpecah ${ }^{11}$. Dari beberapa faktor tersebut dapat menyebabkan tingginya angka insiden di unit tersebut ${ }^{12}$.

Beban kerja menjadi hal yang penting untuk diperhatikan karena dengan beban kerja yang tinggi dapat menyebabkan penurunan produktivitas akibat kelelahan dan dapat memengaruhi kesehatan mental dari karyawan di rumah sakit, sehingga rumah sakit dapat melakukan perhitungan kembali tentang ketenagaan di rumah sakit dengan melihat tata letak ruang rumah sakit, jumlah kunjungan dan kegiatan apa saja yang ada di unit kerja tersebut ${ }^{13,14}$.

Beban kerja harus diperhatikan oleh suatu organisasi karena beban kerja merupakan salah satu faktor yang dapat meningkatkan produktivitas kerja pekerja ${ }^{15}$. Selain itu, unsur lain yang harus diperhatikan bagi seorang tenaga kerja untuk mendapatkan keserasian dan produktivitas kerja yang tinggi

adalah beban tambahan akibat lingkungan kerja dan kapasitas kerja ${ }^{16}$.

\section{Komunikasi}

Komunikasi adalah proses membangun realitas bersama melalui interaksi sosial ${ }^{3}$. Standar keselamatan pasien Rumah Sakit ke tujuh dan tujuan keselamatan pasien menurut Joint Commission International (JCI) pada tahun 2019 yaitu komunikasi antar pemberi layanan kesehatan merupakan kunci bagi staf untuk mencapai keselamatan pasien ${ }^{2}$. Insiden Keselamatan Pasien, yang terjadi karena adanya komunikasi yang salah, dapat dicegah dengan melakukan komunikasi yang baik dan efektif. Salah satu aspek penting dalam komunikasi adalah keterbukaan komunikasi antara layanan kesehatan ${ }^{18}$.

Gambaran komunikasi yang terjadi di unit kerja dapat dilihat pada Tabel 1 . Tabel 1 menunjukkan bahwa dari 18-unit kerja layanan di RSI Ahmad Yani, terdapat 11-unit kerja $(61,1 \%)$ dengan tingkat komunikasi yang kurang baik terkait insiden keselamatan pasien. Unit kerja dengan kemampuan komunikasi paling kurang adalah hemodialisis. Merujuk informasi pada Tabel 1, unit kerja hemodialisis memiliki beban kerja yang tinggi, sehingga dapat berdampak pada pola komunikasi yang tidak berjalan dengan baik. Komunikasi yang kurang baik dari petugas kesehatan dapat berdampak pada terjadinya insiden keselamatan pasien. Komunikasi merupakan penentu keberhasilan proses perawatan, apabila komunikasi berjalan dengan baik maka dapat mengurangi kesalahan yang dapat mengakibatkan

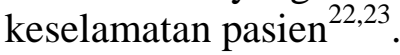

Sementara itu, efek komunikasi terhadap insiden keselamatan pasien disusun dalam tabulasi silang dengan analisis menggunakan pendekatan konsep pareto 20:80. Artinya, apabila terdapat selisih > $20 \%$, maka terdapat pengaruh komunikasi terhadap insiden keselamatan pasien. Hasil selengkapnya tersaji pada Tabel 4 berikut ini.

Tabel 4. Analisis Beban Kerja Terhadap Insiden Keselamatan Pasien

\begin{tabular}{llr}
\hline \multirow{2}{*}{ Komunikasi } & \multicolumn{2}{c}{ Insiden Keselamatan } \\
\cline { 2 - 2 } Pasien & Total \\
\cline { 2 - 3 } & Rendah Tinggi & \\
\hline
\end{tabular}




\begin{tabular}{lccc}
\hline & $\mathbf{n}(\boldsymbol{\%})$ & $\mathbf{n}(\boldsymbol{\%})$ & $\mathbf{n}(\boldsymbol{\%})$ \\
\hline Baik & 6 & 1 & 7 \\
& $(85,7)$ & $(14,3)$ & $(100,0)$ \\
\hline Kurang & 6 & 5 & 11 \\
& $(54,5)$ & $(45,5)$ & $(100,0)$ \\
\hline Total & 12 & 6 & 18 \\
& $(66,7)$ & $(33,3)$ & $(100,0)$ \\
\hline
\end{tabular}

Tabel 4 memberikan informasi bahwa semakin baik komunikasi yang dilakukan unit kerja, maka semakin rendah tingkat insiden keselamatan pasien yang terjadi $(85,7 \%)$. Sedangkan komunikasi yang terjalin kurang baik dapat berdampak pada tingginya insiden keselamatan pasien $(45,5 \%)$. Berdasarkan hasil tabulasi silang, dapat dilihat selisih kategori pada komunikasi mencapai 31,2\% $(>20 \%)$. Oleh sebab itu, dapat disimpulkan bahwa komunikasi memengaruhi insiden keselamatan pasien.

Komunikasi antar pemberi layanan kesehatan merupakan kunci bagi staf untuk mencapai keselamatan pasien $^{17}$. Insiden Keselamatan Pasien karena komunikasi yang salah dapat dicegah dengan komunikasi yang baik dan efektif, salah satu variabel penting dalam komunikasi adalah keterbukaan komunikasi antara pemberi layanan kesehatan $^{18}$.

Pada penelitian ini, kepala unit merupakan pemimpin yang diharapkan mampu memberikan arahan dan mendengarkan setiap permasalahan yang ada di unit kerjanya. Beberapa hambatan sering ditemui, tetapi tidak pernah menjadikan hal tersebut sebagai masalah yang besar. Oleh sebab itu, diperlukan sebuah upaya untuk mengetahui peran kegagalan komunikasi dalam perawatan kesehatan, dengan mencoba memahami lebih baik beberapa komponen dasar dalam proses komunikasi ${ }^{19}$.

Hasil penelitian terkait komunikasi di unit kerja menunjukkan sebagian besar komunikasi di unit kerja masuk dalam kategori rendah sebesar $61,1 \%$ dengan selisih persentase sebesar 31,2\%. Artinya, komunikasi memberikan pengaruh terhadap angka insiden keselamatan pasien di RS Islam Surabaya. Rendahnya komunikasi akan menyebabkan terjadinya kesenjangan komunikasi dan kurangnya informasi, sehingga proses upaya perbaikan juga akan terhalang ${ }^{20}$.

Komunikasi dengan berbagai pihak untuk mencapai tujuannya sangat perlu dilakukan, namun perlu diketahui bahwa pendekatan yang dipakai antara satu organisasi dengan organisasi yang lain dapat berbeda-beda. Bagi rumah sakit yang hanya memiliki beberapa karyawan, maka penyampaian informasi kepada mereka merupakan suatu pekerjaan yang cukup rumit $^{21}$. Hal ini mungkin dapat menjadi beban tambahan, bila mereka sebelumnya sudah mengemban beban yang cukup tinggi. Komunikasi yang rendah dengan angka insiden yang tinggi sering kali terjadi di unitunit kerja layanan kesehatan yang mempunyai jumlah kunjungan yang tinggi, sehingga proses komunikasi tidak berjalan dengan baik. Keterbukaan di dalam berkomunikasi sangat diperlukan agar informasi tersampaikan dengan sepenuhnya. Keterbukaan yang dimaksud adalah staf tidak boleh takut dalam menyampaikan masalah yang ada di dalam unit kerja maupun menyampaikan saran, baik sesama staf maupun staf dengan atasan ${ }^{15}$.

Hasil penelitian yang telah dilakukan menunjukkan bahwa keterbukaan komunikasi yang rendah sering kali terjadi antar staf di unit kerja. Staf dinilai lebih berani berkomunikasi terkait insiden keselamatan terhadap atasannya secara langsung daripada berkomunikasi dengan sesama staf. Penyebabnya, keterbukaan komunikasi antar staf lebih dianggap menggurui satu sama lain atau adanya perasaan tidak enak. Komunikasi yang terbuka dalam keselamatan pasien menjadi sesuatu yang penting dalam komunikasi organisasi dan menjadi langkah awal dalam penyelesaian masalah insiden keselamatan pasien.

\section{KESIMPULAN}

Mayoritas unit kerja di RS Islam Surabaya Ahmad Yani mempunyai aspek beban kerja yang rendah, sedangkan aspek komunikasi masih dinilai belum baik. Di samping itu, insiden keselamatan pasien di rumah sakit didominasi oleh Kejadian Nyaris Cidera (KNC) dengan grading hijau dan angka insiden paling tinggi berada pada unit rawat jalan. Penelitian ini menunjukkan 
bahwa insiden keselamatan pasien di rumah sakit dapat dipengaruhi oleh komunikasi, sedangkan beban kerja tidak berpengaruh terhadap insiden keselamatan pasien. Oleh sebab itu, rumah sakit sangat perlu untuk membenahi pola dan alur komunikasi serta adanya keterbukaan informasi agar arus informasi menjadi lebih adekuat, transfer pengetahuan menjadi lebih baik dan pemahaman pegawai akan pentingnya keselamatan pasien di rumah sakit menjadi lebih baik, serta angka insiden keselamatan pasien dapat turun.

\section{UCAPAN TERIMA KASIH}

Penulis mengucapkan terima kasih kepada Rumah Sakit Islam Surabaya Ahmad Yani atas ijin yang diberikan serta kepada seluruh responden yang bersedia berpartisipasi pada penelitian ini.

\section{DAFTAR PUSTAKA}

1. Munandar. Stress dan Keselamatan Kerja Psikologi Industri. Jakarta: Universitas Indonesia; 2001.

2. JCI. Patient Safety: Essential For Health Care. New York City: Joint Comission Resource; 2005.

3. Retnaningsih D, Fatmawati D. Beban Kerja Perawat Terhadap Implementasi Patient Safety di Ruang Rawat Inap. J Keperawatan Soedirman. 2016;11(1):4452.

4. Yarnita Y, Maswarni M. Budaya Keselamatan Pasien pada Perawat di Instalasi Perawatan Intensive RSUD Arifin Achmad Provinsi Riau. J Keperawatan Prior. 2019;2(2):109-19.

5. Wianti A, Setiawan A, Murtiningsih, Budiman, Rohayani L. Karakteristik dan Budaya Keselamatan Pasien terhadap insiden keselamatan pasien. J Keperawatan Silampari. 2021;5(1):96102.

6. Gittel J. A Relational Model of High Performance Work System Work. New York: Organization Science; 2010.

7. Hariyanti M. Pengaruh Beban Kerja terhadap Kelelahan Kerja pada Pekerja Linting Manual di PT Djitoe Indonesia Tobacco Surakarta. Surakarta: Fakultas Ilmu Kesehatan UMS;
8. Sunarto, Santoso H. Buku Saku Analisis Pareto. Surabaya: Poltekkes Kemenkes Surabaya; 2020.

9. Effendy OU. Dinamika Komunikasi. Bandung: PT. Remaja; 2008.

10. Ivancevic $\mathrm{K}$, Matteson. Perilaku dan Manajemen Organisasi. Jakarta: Erlangga; 2007.

11. Benn J, Koutantji M, Wallace L, Spurgeon P, Rejman M, Healey A, et al. Feedback from incident reporting: information and action to iprove patient safety, Clinical safety research unit. London: Imperial College; 2015.

12. Miner MH, Dowson M, Griffin B. Spiritual Resources and Work Engagement Among Religious Workers: A Three_Wave Longitudinal Study. Ocupational Organitational J. 2014;87(2):370-91.

13. Purwanto. Komunikasi antar Lawan Bicara. Jakarta: Erlangga; 2016.

14. Ilyas Y. Kiat Sukses Manajemen Tim Kerja. Jakarta: PT. Gramedia Pustaka Utama; 2013.

15. Timperley H, Robinson V. The Power of Umpan Balik Workload and the Professional Culture of Teachers. Manag Adm Leadersh Early Career Reseacher. 2000;12(1):200-23.

16. Isyandi B. Manajemen Sumber Daya Manusia Dalam Perspektif Global. Bandung: Press Publisher; 2004.

17. Manser T. Teamwork and patient safety in dynamic domains of healthcare: a review of the literature. Acta Anesth Scand. 2007;53(2):143-51.

18. Schein EH. Organizational Culture and Leadership. San Francisco: Jossey Bass; 1992.

19. Carayon P. Systems Engineering Initiative for Patient Safety (SEIPS)Center for Quality and Productivity Improvement and Department of Industrial Engineer-ing. Hum Factors Organ Des Manag. 2003;7(12):21-30.

20. Funke G, Knott BEDA. Conceptualization and Measurement of Team Workload A Critical Need. Hum Factors J Hum Factors Ergon Soc. 2016;58(2):36-51. 
21. Riviwanto $\mathbf{M}$, Imam S. Konsep dan Pendekatan Rumah. Kasjono HS, editor. Yogyakarta: Gosyen Publishing; 2011. 10

p.

22. Gandhi TK, Graydon BE, Huber CN. Closing the Loop: Followup and Umpan Balik in a Patient Safety Program. J Qual Patient Saf. 2005;31(1):11-23.

23. Henriksen K, Margaret A. Understanding Adverse Events: A Human Factors Framework in quality. In: Patient Safety and Quality:Evidence-Based Handbook for Nurses. United States: AHRQ Publication; 2018.

24. Walton M. The WHO Patient Safety Curriculum Guide For Medical Schools. Qual Saf Heal Care. 2010;1(19):55425246.

25. Jannah N. Hubungan Antara Beban Kerja dengan Kelelahan Kerja pada Karyawan Bagian Cutting Pt. Dan Liris Banaran Kabupaten Sukoharjo. Surakarta: Fakultas Ilmu Kesehatan UMS. 2014. 